Research Paper

\title{
Extract of Ginkgo Biloba Ameliorates Streptozotocin- Induced Type 1 Diabetes Mellitus and High-Fat Diet- Induced Type 2 Diabetes Mellitus in Mice
} \author{
Jung $2,3, \llbracket$ \\ 1. Department of Biomedical Laboratory Science, College of Health Sciences, Yonsei University at Wonju \\ 2. Department of Animal Science, North Carolina State University \\ 3. College of Veterinary Medicine \& Institute of Veterinary Science, Kangwon National University
}

Ki-Jong Rhee ${ }^{1}$, Chang Gun Lee1, Sung Woo Kim², Dong-Hyeon Gim³, Hyun-Cheol Kim³, Bae Dong

$\square$ Corresponding author: Bae Dong Jung, DVM, PhD, College of Veterinary Medicine, Kangwon National University, Chuncheon, Gangwon-do, Republic of Korea, 200-701. bdjung@kangwon.ac.kr; Tel: +82-33-250-8674; FAX: +82-33-244-2367

(C) 2015 Ivyspring International Publisher. Reproduction is permitted for personal, noncommercial use, provided that the article is in whole, unmodified, and properly cited. See http://ivyspring.com/terms for terms and conditions.

Received: 2015.07.26; Accepted: 2015.11.09; Published: 2015.11.23

\begin{abstract}
Diabetes mellitus (DM) is caused by either destruction of pancreatic $\beta$-cells (type 1 DM) or unresponsiveness to insulin (type 2 DM). Conventional therapies for diabetes mellitus have been developed but still needs improvement. Many diabetic patients have complemented conventional therapy with alternative methods including oral supplementation of natural products. In this study, we assessed whether Ginkgo biloba extract (EGb) 761 could provide beneficial effects in the streptozotocin-induced type 1 DM and high-fat diet-induced type 2 DM murine model system. For the type 1 DM model, streptozotocin-induced mice were orally administered EGb 761 for 10 days prior to streptozotocin injection and then again administered EGb 761 for an additional 10 days. Streptozotocin-treated mice administered EGb 761 exhibited lower blood triglyceride levels, lower blood glucose levels and higher blood insulin levels compared to streptozotocin-treated mice. Furthermore, liver LPL and liver PPAR- $\alpha$ were increased whereas IL-1 $\beta$ and TNF- $\alpha$ were decreased in streptozotocin-injected mice treated with EGb 761 compared to mice injected with streptozotocin alone. For the type 2 DM model, mice were given high-fat diet for 60 days and then orally administered EGb 761 every other day for 80 days. We found that mice given a high-fat diet and EGb 761 showed decreased blood triglyceride levels, increased liver LPL, increased liver PPAR- $\alpha$ and decreased body weight compared to mice given high-fat diet alone. These results suggest that EGb 761 can exert protective effects in both type 1 and type 2 DM murine models.
\end{abstract}

Key words: diabetes mellitus, extract of Gingko biloba, streptozotocin, high-fat diet

\section{Introduction}

Diabetes mellitus (DM) is a metabolic disease caused in part by lack of insulin secretion by pancreatic $\beta$-cells or by lack of responsiveness to insulin. Diabetes mellitus is classified into two groups: type 1 DM and type $2 \mathrm{DM}$. Of these two types, type $2 \mathrm{DM}$ is more prevalent [1]. Type $1 \mathrm{DM}$ is caused by destruction of the pancreatic $\beta$-cells resulting in lack of insulin secretion and is accompanied by high blood glucose concentrations and ketoacidosis [2]. Type $2 \mathrm{DM}$ is caused by obesity and is accompanied by high blood insulin levels and hyperlipidemia [3-6]. Complete treatment of diabetes mellitus is difficult but can be managed and further progression delayed by maintaining optimal blood glucose levels. Many diabetes patients use regular exercise and diet to augment their diabetes therapy $[7,8]$. However, increasing numbers of patients with diabetes have turned to consumption of natural products to complement existing traditional therapy.

Ginkgo biloba is a tree native East Asia and extracts derived from the Ginkgo tree have been used for traditional medicinal purposes. Although several 
biologically active components have been described in the literature, the predominant pharmacologically active components in Ginkgo biloba include flavonols and terpene trilactones $[9,10]$. However, the therapeutic effects EGb are likely not attributed to any one compound but rather the combined effect of several components in the whole extract [11, 12]. Several commercialized Ginkgo biloba extracts exist but the EGb 761 extract is by the well-standardized product. EGb is purported be exert beneficial effects in Alzheimer's disease, cancer, colitis, vascular diseases and oxidative stress [10, 12-15]. At the molecular level, $\mathrm{EGb}$ is thought to exert protective and antioxidative effects through upregulation of superoxide dismutase (SOD) and glutathione (GSH) expression which in turn suppresses synthesis of reactive oxygen species (ROS) [16, 17]. In addition, intraperitoneal injection of EGb in rats inhibits expression of proinflammatory cytokines such as tumor necrosis factor- $\alpha$ (TNF- $\alpha$ ) thereby ameliorating inflammation [18]. It has also been reported that EGb administration can regulate fatty acid metabolism and increased circulating non-saturated fatty acids $[19,20]$. In a streptozotocin-induced rat diabetes model, EGb 761 suppressed diabetic cardiomyopathy [21]. Collectively, these results suggest that EGb may be an effective therapy for preventing and/or treatment of diabetes. In the current study, we evaluated the efficacy of EGb in STZ-induced type $1 \mathrm{DM}$ and high fat diet induced type $2 \mathrm{DM}$.

\section{Materials and Methods}

\section{Induction of murine diabetes mellitus}

For streptozotocin-induced type $1 \mathrm{DM}$ studies, 7-week-old male C57BL/6 mice (Bio Genomic Inc. Charles River Technology, Gapyung-Gun, Gyeonggi-Do, South Korea) weighing $23 \pm 1$ grams were used. Mice were administered EGb 761 (50 mg/ $\mathrm{kg}$, p.o.) once a day for 10 consecutive days and then injected once with STZ $(120 \mathrm{mg} / \mathrm{kg}$, i.p.)(Sigma-Aldrich, St. Louis, MO, USA). Thereafter, mice were re-administered EGb 761 (50 mg/ kg, p.o.) again daily for an additional 10 days. Mice were sacrificed one day after the final EGb dose. Blood was collected from retro-orbital veins. Body weight measurements were taken daily. Food and water were provided ad labitum. For high-fat diet-induced type 2 DM studies, 7-week-old male,C57BL/ 6 mice weighing 19 \pm 1 grams were used. Mice were provided either normal diet (SAM\#31, Samtako, Osan, Korea) or high-fat diet (D12451, Research Diet, Inc.) for 140 days. At day 60, a subset of mice was administered EGb $(50 \mathrm{mg} / \mathrm{kg}$, p.o.) or saline every two days for the duration of the experiment (140 days). Blood was collected from ret- ro-orbital veins. Body weight measurements were taken daily. Food and water were provided ad labitum. All animal protocols were approved by the Institutional Animal Care and Use Committee (IACUC) of Kangwon National University (IACUC\# KW-150512-2).

\section{Western blot analysis}

Tissues were homogenized in lysis buffer containing 10\% SDS and phosphatase inhibitor cocktail (A.G. Scientific Inc., CA, USA). Lysates were clarified at $12000 \mathrm{rpm}, 4^{\circ} \mathrm{C}$ for $20 \mathrm{~min}$. Proteins were electrophoresed, transferred to nitrocellulose membranes and probed overnight with specific antibodies against $\beta$-actin , LPL, PPAR- $\alpha$, p-HSL, HSL, IL-1 $\beta$, IL-6 or TNF- $\alpha$ as described previously [22]. Immunoblots were washed extensively and probed with appropriate horse-radish peroxidase conjugated secondary antibodies. Bands were visualized using Pierce ${ }^{\circledR}$ ECL Plus Western Blotting Substrate (Lumigen, Inc. Southfield, MI, USA).

\section{Assessment of blood glucose, insulin and tri- glyceride}

Blood glucose levels were evaluated using ACCU-CHEK Go (Roche Diagnostics Inc., Korea). Blood insulin levels were evaluated using insulin kit (Shinbayagi Co., Shinbukawa, Gunma, Japan). Blood triglyceride was evaluated using Acechem TG kit (YD Diagnostics Inc., Korea).

\section{Statistical Analysis}

Statistical analyses were performed using one-way analysis of variance (ANOVA) or repeated measure one-way ANOVA. A post-hoc Fisher's PLSD test was then applied. $p<0.05$ was deemed to indicate statistical significance.

\section{Results}

\section{Body weight change}

In the streptozotocin-induced type $1 \mathrm{DM}$ mice, the streptozotocin +saline $(S t z+S)$ group and the streptozotocin+EGb $761(\mathrm{Stz}+\mathrm{E})$ group showed a statistically significant decrease in body weight compared to the streptozotocin untreated groups at day 20 $(p<0.05)$ (Table 1). There was no difference in the body weight between the Stz+S and Stz+E groups. In the high-fat type $2 \mathrm{DM}$ model, as expected, mice given a high-fat diet + saline $(\mathrm{H}+\mathrm{S})$ showed increased body weight at day 60 and at day 140 compared to mice given a normal diet + saline $(\mathrm{N}+\mathrm{S})(p<0.01)$ (Table 2$)$. Remarkably, at day 140, mice given a high-fat diet+EGb $761(\mathrm{H}+\mathrm{E})$ showed less body weight gain compared to mice given a high-fat diet and saline $(\mathrm{H}+\mathrm{S})(p<0.01)($ Table 2$)$. This result suggests that oral 
administration of EGb 761suppresses body weight gain in the high-fat diet type 2 DM model.

Table 1. Body weight change in streptozotocin-induced type 1 DM mice. Mice were administered EGb 761 (50 mg/kg, p.o.) once a day for 10 consecutive days and then injected once with streptozotocin $(120 \mathrm{mg} / \mathrm{kg}$, i.p.). Thereafter, mice were re-administered EGb 761 (50 mg/kg, p.o.) again daily for an additional 10 days. The body weights are shown as mean \pm SEM of 7 mice. One-way ANOVA followed by Fisher's PLSD test was used for statistical analysis. Stz, streptozotocin; E, EGb 761; S, Saline. $\mathrm{Stz}+\mathrm{S}$ group was compared to $\mathrm{S}+\mathrm{S}$. Stz $+\mathrm{E}$ group was compared to $\mathrm{S}+\mathrm{E}$ group. $* p<0.05$.

\begin{tabular}{llll}
\hline Exp. group & Day 0 & Day 10 & Day 20 \\
\hline S+S & $23.0 \pm 0.6$ & $24.0 \pm 0.2$ & $24.1 \pm 0.2$ \\
S+E & $23.1 \pm 0.5$ & $24.1 \pm 0.4$ & $24.4 \pm 0.4$ \\
Stz+S & $22.5 \pm 0.6$ & $23.0 \pm 0.4$ & $21.8 \pm 0.7^{*}$ \\
Stz+E & $22.7 \pm 0.3$ & $22.6 \pm 0.2$ & $21.0 \pm 0.4^{*}$ \\
\hline
\end{tabular}

Table 2. Body weight change in high-fat diet-induced type 2 DM mice. Mice were provided either normal diet or high-fat diet for 140 days. At day 60, a subset of mice was administered EGb 761 (50 mg/kg, p.o.) or saline every two days for the duration of the experiment. The body weights are shown as mean \pm SEM of 7 mice. One-way ANOVA followed by Fisher's PLSD test was used for statistical analysis. N, normal diet; $\mathrm{H}$, high-fat diet; $\mathrm{E}, \mathrm{EGb} 761$; $\mathrm{S}$, Saline. Statistical significance was found for high-fat diet+saline group versus normal diet+saline group (day 60), high-fat diet+EGb 761 group versus normal diet+EGb 761 group (day 60), high-fat diet+saline group versus normal diet+saline (day 140), high-fat diet+EGb 761 group versus high-fat diet+saline group (day 140). $* * p<0.01$.

\begin{tabular}{llll}
\hline Exp. groups & Day 0 & Day 60 & Day 140 \\
\hline $\mathrm{N}+\mathrm{S}$ & $19.3 \pm 0.6$ & $27.2 \pm 0.6$ & $33.3 \pm 0.7$ \\
$\mathrm{~N}+\mathrm{E}$ & $18.8 \pm 0.5$ & $26.2 \pm 0.7$ & $34.1 \pm 0.4$ \\
$\mathrm{H}+\mathrm{S}$ & $19.2 \pm 0.4$ & $31.6 \pm 1.1^{* *}$ & $45.4 \pm 0.9^{* *}$ \\
$\mathrm{H}+\mathrm{E}$ & $18.5 \pm 0.4$ & $31.2 \pm 0.9^{* *}$ & $40.9 \pm 1.1^{* *}$ \\
\hline
\end{tabular}

\section{Blood triglyceride levels}

Blood triglyceride levels were assessed in the DM murine model. As expected, in the streptozotocin-induced type 1 DM model, blood triglyceride lev-

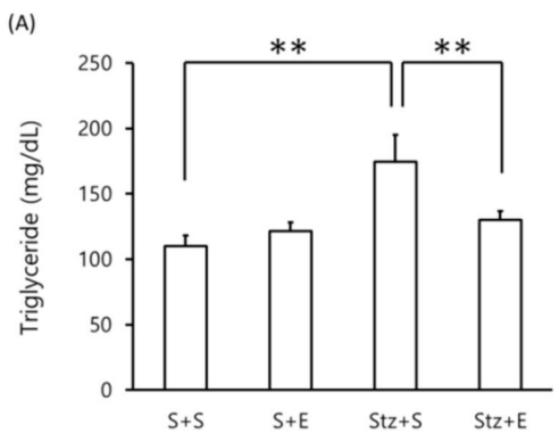

els were increased at day 20 compared to mice administered saline or EGb 761 alone $(p<0.01)$ (Figure 1A). Interestingly, mice administered streptozotocin+EGb 761 exhibited lower levels of blood triglyceride compared to mice given streptozotocin alone ( $p$ $<0.01$ )(Figure 1A). In the high-fat diet-induced type 1 DM model, mice given a high-fat diet alone showed an increase in blood triglyceride levels compared to mice given a normal diet $(p<0.01)$ (Figure 1B). However, mice co-administered EGb 761 with the high-fat diet showed a decrease in blood triglyceride levels compared to mice given high-fat diet alone $(p$ $<0.05$ )(Figure 2B). These results suggest that EGb 761 suppresses blood triglyceride levels in both type 1 DM and type 2 DM models.

\section{Blood glucose and insulin levels}

We next evaluated the effect of EGb 761 on blood glucose and blood insulin levels in type $1 \mathrm{DM}$ and type $2 \mathrm{DM}$ mice. As expected, mice given streptozotocin alone exhibited an increase in blood glucose levels and a decrease in blood insulin levels compared to mice given saline alone $(p<0.01)$ (Figure 2A). However, mice co-administered EGb 761 in streptozotocin-injected mice showed decreased blood glucose and increased blood insulin levels $(p<0.05)$ compared to streptozotocin-induced mice (Figure $2 \mathrm{~A})$. These results suggest that EGb 761 administration ameliorates streptozotocin-induced type 2 DM. In the high-fat DM model, mice given a high-fat diet exhibited increased levels of blood glucose and increased levels of blood insulin compared to mice given a normal diet $(p<0.05)$ (Figure 2B). In contrast, high-fat diet mice co-administered EGb 761 showed no change in blood glucose and insulin levels compared to mice injected with streptozotocin alone (Figure 2B). These results demonstrate that EGb 761 exerted a protective effect in the streptozotocin-induced type $1 \mathrm{DM}$ model but not in the high-fat diet-induced type 2 DM model.

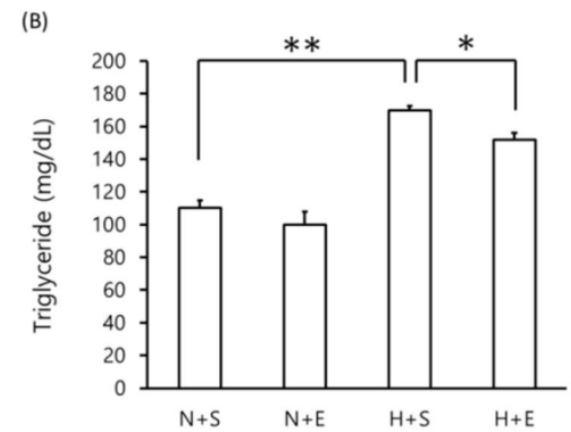

Figure 1. Blood triglyceride levels in DM mice. Blood triglyceride levels were measured in (A) streptozotocin-induced type 1 DM mice at day 20 and (B) high-fat diet-induced type 2 DM mice at day 140. Data is shown as the mean $\pm S E M$ of 7 mice. One-way ANOVA followed by Fisher's PLSD test was used for statistical analysis. S, saline; E, EGb 761; Stz, streptozotocin; N, normal diet; H, high-fat diet. Statistical significance are shown for Stz+S vs S+S, Stz+E vs $\mathrm{Stz}+\mathrm{S}, \mathrm{H}+\mathrm{S}$ vs $\mathrm{N}+\mathrm{S}, \mathrm{H}+\mathrm{E}$ vs $\mathrm{H}+\mathrm{S}$. $* p<0.05$, ** $p<0.01$. 

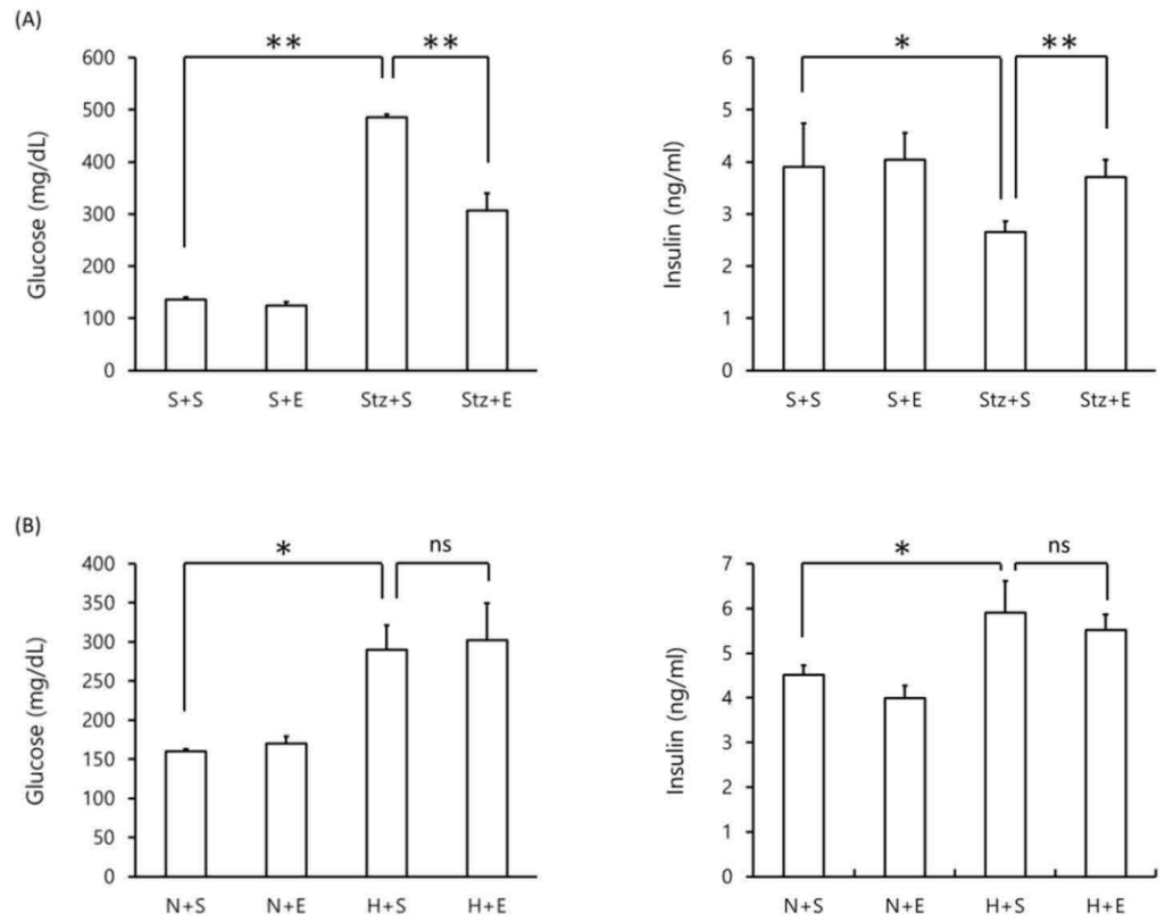

Figure 2. Blood glucose and insulin levels in DM mice. Blood glucose (left panel) and insulin (right panel) levels were measured in (A) streptozotocin-induced type $1 \mathrm{DM}$ mice at day 20 and (B) high-fat diet-induced type $2 \mathrm{DM}$ mice at day 140. Data is shown as the mean \pm SEM of 7 mice. One-way ANOVA followed by Fisher's PLSD test was used for statistical analysis. S, saline; E, EGb 761; Stz, streptozotocin; N, normal diet; H, high-fat diet. Statistical significance are shown for $\mathrm{Stz}+\mathrm{S}$ vs $\mathrm{S}+\mathrm{S}$, Stz+E vs $\mathrm{Stz}+\mathrm{S}, \mathrm{H}+\mathrm{S}$ vs $\mathrm{N}+\mathrm{S}, \mathrm{H}+\mathrm{S}$ vs $\mathrm{N}+\mathrm{S}$. ${ }^{*} p<0.05$, $* * p<0.01$, ns $=$ not significant.

\section{Effects of EGb 761 in levels of LPL, PPAR- $\alpha$ and proinflammatory proteins in type $1 \mathrm{DM}$ mice}

We evaluated changes in proteins levels of LPL, PPAR- $\alpha$ and proinflammatory proteins in type $1 \mathrm{DM}$ mice. Mice injected with streptozotocin showed a decrease in liver LPL levels compared with mice injected with saline alone ( $p<0.01)$ (Figure 3A). Co-administration of EGb 761 in streptozotocin-induced mice increased LPL levels in the liver compared to mice injected with streptozotocin alone (Figure 3A). Similarly, liver PPAR- $\alpha$ protein levels decreased in streptozotocin-induced mice but reached normal levels in streptozotocin+EGb 761 treated mice (Figure 3B). We next evaluated levels of pro-inflammatory cytokines in the pancreas of streptozotocin-induced mice. Mice injected with streptozotocin exhibited elevated levels of IL-1 $\beta$, IL- 6 and TNF- $\alpha$ in the pancreas compared to untreated mice (Figure 3C, D, E). Co-administration of EGb 716 in streptozotocin-induced mice increased levels of IL-1 $\beta$ and TNF- $\alpha$ but not IL- 6 in the pancreas (Figure 3C, D, E). These results suggest that EGb 761 treatment decreased pancreatic inflammation in streptozotocin-injected mice.

\section{Effects of EGb 761 in levels of LPL, PPAR- $\alpha$ and proinflammatory proteins in type $2 \mathrm{DM}$ mice}

In mice given a high-fat diet, protein levels of phosphorylated HSL in the liver remained unchanged compared to mice given a normal diet (Figure 4A). However, both LPL and PPAR- $\alpha$ levels decreased in the liver of mice given a high-fat diet (Figure 4B, C). Administration of EGb 761 in high-fat diet mice elevated liver LPL and liver PPAR- $\alpha$ protein levels (Figure $4 \mathrm{~B}, \mathrm{C})$. In contrast, high-fat diet mice exhibited no change in protein levels of muscle LPL and muscle PPAR- $\alpha$ levels nor did additional EGb 761 administration (Figure 4D, E).

\section{Discussion}

Streptozotocin causes destruction of pancreatic $\beta$-cells which results in decreased insulin production. As a result, fatty acid is released from adipose tissues accompanied by increase ketone synthesis and progression to ketosis [23]. Furthermore, triglyceride does not enter cells and thus blood triglyceride levels are increased [24]. The increased serum triglyceride is normally lowered by hydrolysis of triglyceride into free fatty acid and glycerol. This process requires the lipoprotein lipase. Peroxisome proliferator-activated receptor $\alpha$ is involved in metabolism of fatty acid in 
the liver, kidney, heart, skeletal muscle, etc. Especially, LPL is highly expressed in the liver which then metabolizes the fatty acid [25]. Streptozotocin is also known to inhibit synthesis of LPL in the liver [26]. Insulin induces expression of PPAR- $\alpha$ and LPL, stimulates preadipocyte proliferation and differentiation and metabolism of adipose tissue [27]. In the current study, we found that streptozotocin injection resulted in decreased protein levels of LPL and PPAR- $\alpha$ in the liver. However, administration of EGb 761 enhanced protein levels of both liver LPL and liver PPAR- $\alpha$ in the streptozotocin-induced model. In addition, we

(A)

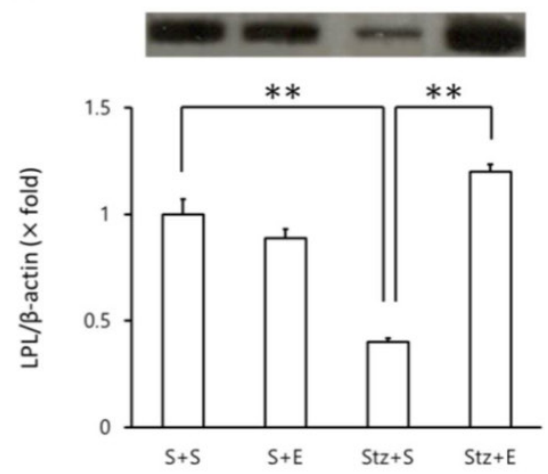

(C)

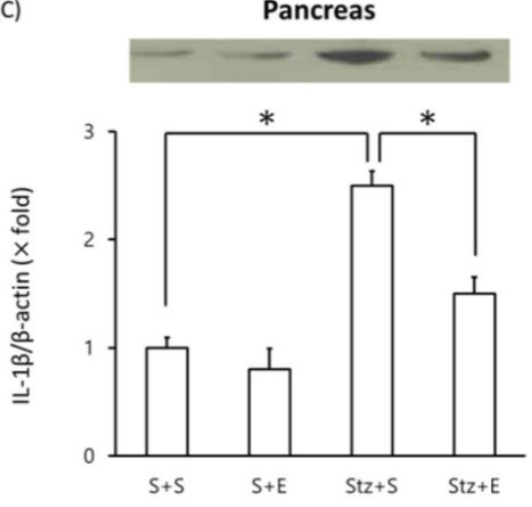

(E)

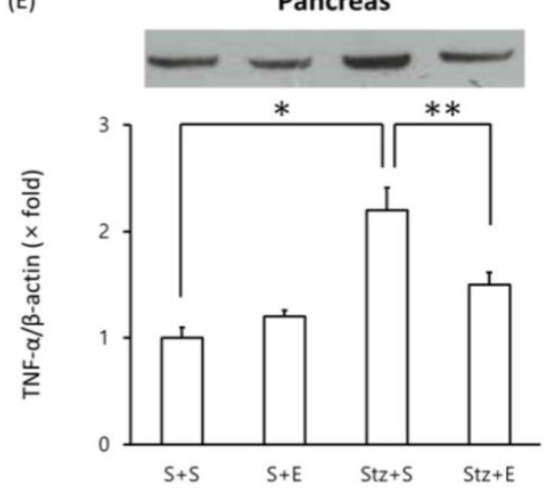

found that in the streptozotocin-induced type $1 \mathrm{DM}$ mice, co-administration of EGb 761 resulted in decreased blood triglyceride and blood glucose levels and recovery of blood insulin levels compared mice injected with streptozotocin alone. This data is consistent with the results showing that EGb can decrease triglyceride levels [28]. Therefore, EGb 761 appears to exert a protective effect against type $1 \mathrm{DM}$ in the streptozotocin-induced DM model. Administration of EGb 761 at did not by itself induce any gross deleterious effects on mice upon examination of the liver, spleen, intestines, lung and brain (data not shown).

(B)

Liver
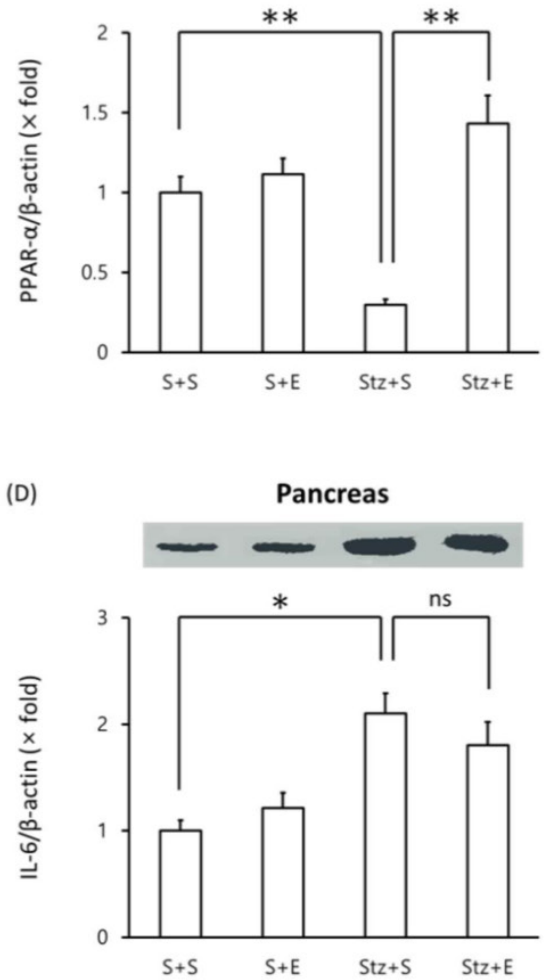

Figure 3. Western blot analysis of proteins in streptozotocin-induced type 1 DM mice. Tissue lysates were prepared and analyzed by Western blot analysis. (A) liver LPL, (B) liver PPAR $\alpha$, (C) pancreas IL-1 $\beta$, (D) pancreas IL-6, (E) pancreas TNF- $\alpha$. One representative immunoblot (upper panel) and densitometric analysis of five samples (lower panel, mean \pm SEM) are shown. One-way ANOVA followed by Fisher's PLSD test was used for statistical analysis. S, saline; E, EGb 761; Stz, streptozotocin. $*_{p}<0.05$, $* * p<0.01$, ns $=$ not significant. 

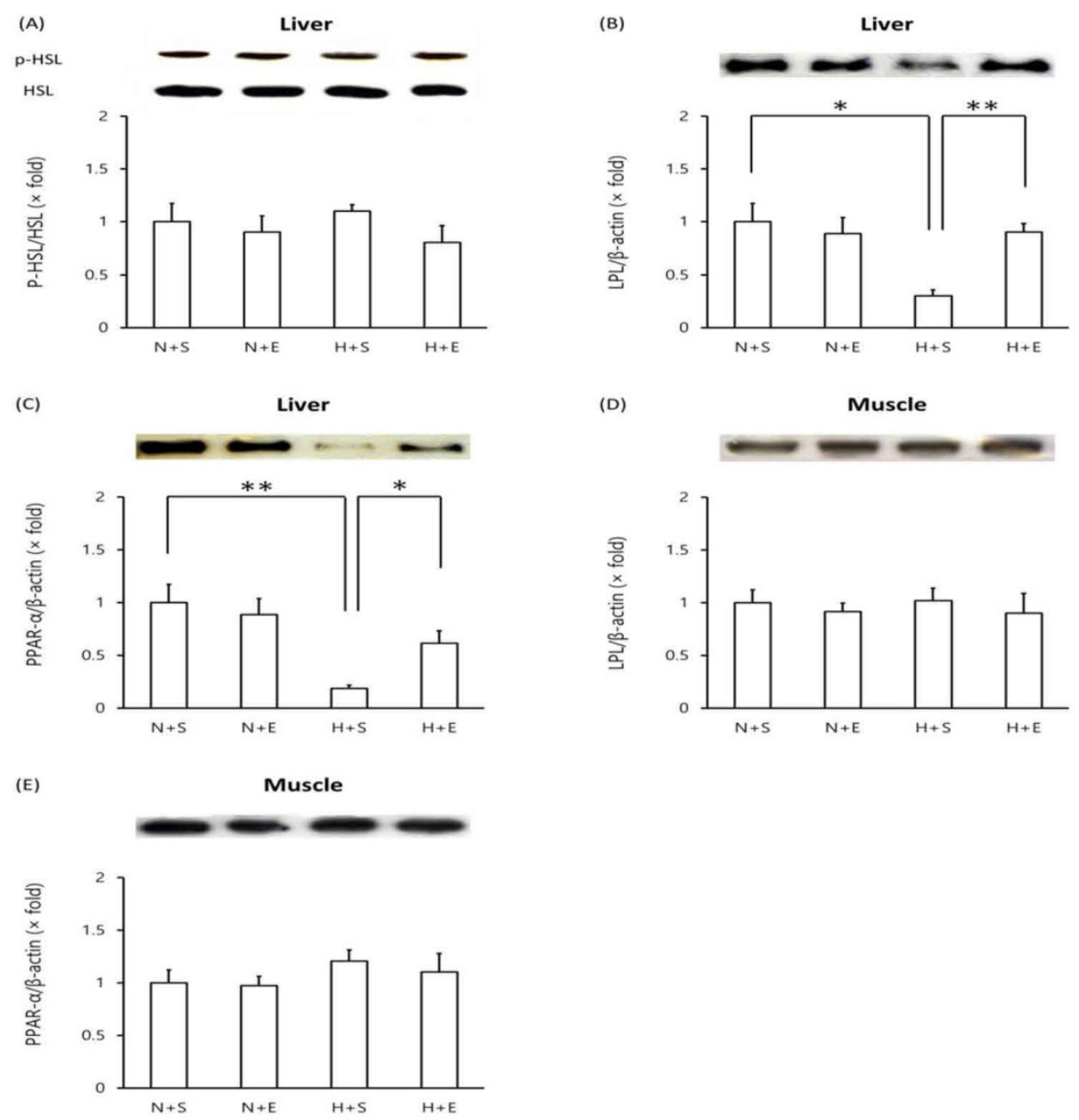

Figure 4. Western blot analysis of proteins in high-fat diet-induced type 2 DM mice. Tissue lysates were prepared and analyzed by Western blot analysis. (A) liver phosphorylated-HSL vs total HSL, (B) liver LPL, (C) liver PPAR $\alpha$, (D) muscle LPL, (E) muscle PPAR $\alpha$. One representative immunoblot (upper panel) and densitometric analysis of five samples (lower panel, mean \pm SEM) are shown. One-way ANOVA followed by Fisher's PLSD test was used for statistical analysis. S, saline; E, EGb 761; N, normal diet; $\mathrm{H}$, high-fat diet. $* p<0.05$, ** $p<0.01$, ns $=$ not significant.

Injection of streptozotocin causes pancreatic inflammation with concomitant increase in pro-inflammatory cytokines $[29,30]$. In the current study, we found that EGb 761 administration also decreased levels of the pro-inflammatory cytokines IL-1 $\beta$ and TNF- $\alpha$ in the pancreas of streptozotocin-induced mice. Thus, our data suggests that EGb 761 can alleviate pancreatic damage since administration of EGb 761 in streptozotocin-induced resulted in decreased IL-1 $\beta$ and TNF- $\alpha$ protein levels in the pancreas. This conclusion is consistent with previous studies which demonstrated that EGb decreased pancreatic inflammation and expression of proinflammatory cytokines such as IL- $1 \beta$, TNF- $\alpha$ and IL-6 $[31,32]$. In addition, overexpression of IGF- 1 in $\beta$-cells of transgenic mice conferred recovery from streptozotocin-induced pancreatic damage [33]. It is possible that in our study EGb 761 induced IGF-1 in the pancreas leading to decreased pancreatic damage.
Obesity is the main cause of type 2 diabetes mellitus [34]. In our high-fat diet murine model of type $2 \mathrm{DM}$, mice given a high-fat diet for 140 days exhibited increased body weight, increased blood glucose and increased blood insulin levels. Blood triglyceride levels were also increased. These results confirm that mice given a high-fat diet exhibited all the canonical attributes of type $2 \mathrm{DM}$. In the current study, we found that administration of EGb 761 in high-fat diet mice did not decrease elevated levels of blood glucose nor blood insulin suggesting that EGb 761 does not affect these parameters in the high-fat diet type 2 DM model. However, EGb 761 did decrease body weight gain and blood triglyceride levels in mice fed a high-fat diet. As reported previously, $\mathrm{EGb}$ induces decrease in triglyceride levels [28]. Obesity caused by the high-fat diet results in increased number and size of adipocytes [3, 4]. The enlarged adipocytes are refractive to insulin induce glucose metabolism and glucose transport thereby resulting in 
insulin resistance in peripheral tissues and increased blood insulin levels [35]. Increased insulin resistance causes inhibition of lipoprotein lipase of peripheral tissues [36, 37]. Our study shows that EGb 761 can induce recovery of liver LPL but not muscle LPL.

In the current study, we found that mice given a high-fat diet exhibited decreased protein levels of PPAR- $\alpha$ and LPL in the liver but EGb 761 administration induced recovery of these two proteins. We suggest that EGb induces PPAR- $\alpha$ which in turn induced LPL expression and thus decrease in blood triglyceride levels. However, it is unclear why the PPAR- $\alpha$ and LPL levels in the muscles were unaffected. It is known that tissue distribution of LPL differs among tissues and also fat accumulation in the muscle is lower compared to fat accumulation in adipose tissues [3, 38]. These observations may contribute to the lack of EGb 761 effect in the muscle. Insulin inactivates the hormone-sensitive lipase (HSL), a key enzyme that is involved in hydrolysis of blood triglyceride, thus resulting in accumulation of triglycerides [39]. We examined whether EGb 761 modulated liver HSL expression in the high-fat diet type $2 \mathrm{DM}$ model. There was no difference among the mice given normal diet, high-fat diet and high-fat diet + EGb 761. In high-fat diet type 2 DM model, we found that high-fat diet increased blood insulin levels but did not induce phosphorylated HSL in the liver which is possibility due to insulin resistance.

In conclusion, we found that using the streptozotocin-induced type $1 \mathrm{DM}$ model EGb 761exerted an anti-inflammatory effect in the pancreas resulting in continued synthesis of insulin and consequently decreased blood glucose. Furthermore, EGb 761 decreased PPAR- $\alpha$ and LPL expression which in turn induced decreased levels of blood triglycerides. In the high-fat diet type 2 DM model, EGb 761 decreased body weight gain and increased PPAR- $\alpha$ and LPL expression resulting in decreased blood triglyceride levels. Further mechanistic studies on the effects of EGb on liver PPAR- $\alpha$ and LPL are warranted.

\section{Acknowledgments}

This research was financially supported by Kangwon National University.

\section{Competing Interests}

The authors have declared that no competing interest exists.

\section{References}

1. Kharroubi AT, Darwish HM. Diabetes mellitus: The epidemic of the century. World J Diabetes. 2015; 6: 850-67.

2. Gaba R, Gambhire D, Uy N, Gonzalez EV, Iyer D, Hampe CS, et al. Factors associated with early relapse to insulin dependence in unprovoked A- $\beta+$ ketosis-prone diabetes. J Diabetes Complications. 2015.
3. Kissebah AH, Vydelingum N, Murray R, Evans DJ, Hartz AJ, Kalkhoff RK, et al. Relation of body fat distribution to metabolic complications of obesity. J Clin Endocrinol Metab. 1982; 54: 254-60.

4. Krotkiewski M, Bjorntorp P, Sjostrom L, Smith U. Impact of obesity on metabolism in men and women. Importance of regional adipose tissue distribution. J Clin Invest. 1983; 72: 1150-62.

5. Dwarakanathan A. Diabetes update. J Insur Med. 2006; 38: 20-30.

6. Walker CG, Zariwala MG, Holness MJ, Sugden MC. Diet, obesity and diabetes: a current update. Clin Sci (Lond). 2007; 112: 93-111.

7. Nathan DM, Buse JB, Davidson MB, Ferrannini E, Holman RR, Sherwin R, et al. Management of hyperglycemia in type 2 diabetes: a consensus algorithm for the initiation and adjustment of therapy: update regarding thiazolidinediones: a consensus statement from the American Diabetes Association and the European Association for the Study of Diabetes. Diabetes Care. 2008; 31: 173-5.

8. Turner RC, Cull CA, Frighi V, Holman RR. Glycemic control with diet, sulfonylurea, metformin, or insulin in patients with type 2 diabetes mellitus: progressive requirement for multiple therapies (UKPDS 49). UK Prospective Diabetes Study (UKPDS) Group. JAMA. 1999; 281: 2005-12.

9. van Beek TA, Montoro P. Chemical analysis and quality control of Ginkgo biloba leaves, extracts, and phytopharmaceuticals. J chromatogr A. 2009; 1216: 2002-32.

10. Mohanta TK, Tamboli Y, Zubaidha PK. Phytochemical and medicinal importance of Ginkoo biloba L. Nat Prod Res. 2014; 28: 746-52.

11. Gertz HJ, Kiefer M. Review about Ginkgo biloba special extract EGb 761 (Ginkgo). Curr pharm Des. 2004; 10: 261-4.

12. Mahadevan S, Park Y. Multifaceted therapeutic benefits of Ginkgo biloba L.: chemistry, efficacy, safety, and uses. J Food Sci. 2008; 73: R14-9.

13. Oyama Y, Chikahisa L, Ueha T, Kanemaru K, Noda K. Ginkgo biloba extract protects brain neurons against oxidative stress induced by hydrogen peroxide. Brain res. 1996; 712: 349-52.

14. DeFeudis FV, Drieu K. Ginkgo biloba extract (EGb 761) and CNS functions: basic studies and clinical applications. Curr Drug targets. 2000; 1: 25-58.

15. Silberstein RB, Pipingas A, Song J, Camfield DA, Nathan PJ, Stough C. Examining brain-cognition effects of ginkgo biloba extract: brain activation in the left temporal and left prefrontal cortex in an object working memory task. Evid Based Complement Alternative Med. 2011; 2011: 164139.

16. Marcocci L, Packer L, Droy-Lefaix MT, Sekaki A, Gardes-Albert M. Antioxidant action of Ginkgo biloba extract EGb 761. Methods Enzymol. 1994; 234: 462-75.

17. Bridi R, Crossetti FP, Steffen VM, Henriques AT. The antioxidant activity of standardized extract of Ginkgo biloba (EGb 761) in rats. Phytother Res. 2001; 15: 449-51.

18. Zhou YH, Yu JP, Liu YF, Teng XJ, Ming M, Lv P, et al. Effects of Ginkgo biloba extract on inflammatory mediators (SOD, MDA, TNF-a, NF-KBp65, IL-6) in TNBS-induced colitis in rats. Mediators Inflamm. 2006; 2006: 92642.

19. Zhang Q, Wang GJ, A JY, Wu D, Zhu LL, Ma B, et al. Application of $\mathrm{GC} / \mathrm{MS}$-based metabonomic profiling in studying the lipid-regulating effects of Ginkgo biloba extract on diet-induced hyperlipidemia in rats. Acta Pharmacol Sin. 2009; 30: 1674-87.

20. Drieu K, Vranckx R, Benassayad C, Haourigi M, Hassid J, Yoa RG, et al. Effect of the extract of Ginkgo biloba (EGb 761) on the circulating and cellular profiles of polyunsaturated fatty acids: correlation with the anti-oxidant properties of the extract. Prostaglandins Leukot Essent Fatty Acids. 2000; 63: 293-300.

21. Saini AS, Taliyan R, Sharma PL. Protective effect and mechanism of Ginkgo biloba extract-EGb 761 on STZ-induced diabetic cardiomyopathy in rats. Pharmacogn Mag. 2014; 10: 172-8.

22. Park JB, Lee JS, Cho BP, Rhee K-J, Baik SK, Kim J, Kang SJ, Park D-J, Oh J-E, Shin HC, Kim YM, Kim HS, Bae KS, Eom YW. Adipose tissue-derived mesenchymal stem cells cultured at high cell density express brain-derived neurotrophic factor and exert neuroprotective effects in a 6-hydroxydopamine rat model of Parkinson's disease. Gen Genom. 2015; 37: 213-21.

23. Nagai R, Nagai M, Shimasaki S, Baynes JW, Fujiwara Y. Citric acid inhibits development of cataracts, proteinuria and ketosis in streptozotocin (type 1) diabetic rats. Biochem Biophys Res Commun. 2010; 393: 118-22.

24. Samarghandian S, Azimi-Nezhad M, Samini F. Ameliorative effect of saffron aqueous extract on hyperglycemia, hyperlipidemia, and oxidative stress on diabetic encephalopathy in streptozotocin induced experimental diabetes mellitus. Biomed Res Int. 2014; 2014: 920857.

25. Costet P, Legendre C, More J, Edgar A, Galtier P, Pineau T. Peroxisome proliferator-activated receptor a-isoform deficiency leads to progressive dyslipidemia with sexually dimorphic obesity and steatosis. J Biol Chem. 1998; 273: 29577-85.

26. Li YG, Ji DF, Zhong S, Lin TB, Lv ZQ. Hypoglycemic effect of deoxynojirimycin-polysaccharide on high fat diet and streptozotocin-induced diabetic mice via regulation of hepatic glucose metabolism. Chem Biol Interact. 2015; 225: 70-9.

27. Wang $\mathrm{X}$, Huang $\mathrm{M}$, Wang $\mathrm{Y}$. The effect of insulin, TNFa and DHA on the proliferation, differentiation and lipolysis of preadipocytes isolated from large yellow croaker (Pseudosciaena Crocea R.). PLoS One. 2012; 7: e48069.

28. Yao P, Song F, Li K, Zhou S, Liu S, Sun X, et al. Ginkgo biloba extract prevents ethanol induced dyslipidemia. Am J Chin Med. 2007; 35: 643-52.

29. Koulmanda M, Qipo A, Auchincloss H, Jr., Smith RN. Effects of streptozotocin on autoimmune diabetes in NOD mice. Clin Exp Immunol. 2003; 134: 210-6. 
30. Zheng SJ, Lamhamedi-Cherradi SE, Wang P, Xu L, Chen YH. Tumor suppressor p53 inhibits autoimmune inflammation and macrophage function. Diabetes. 2005; 54: 1423-8.

31. Chen CC, Chiang AN, Liu HN, Chang YT. EGb-761 prevents ultraviolet B-induced photoaging via inactivation of mitogen-activated protein kinases and proinflammatory cytokine expression. J Dermatol Sci. 2014; 75: 55-62.

32. Yin D, Tao J, Lee DD, Shen J, Hara M, Lopez J, et al. Recovery of islet $\beta$-cell function in streptozotocin- induced diabetic mice: an indirect role for the spleen. Diabetes. 2006; 55: 3256-63.

33. George M, Ayuso E, Casellas A, Costa C, Devedjian JC, Bosch F. $\beta$ cell expression of IGF-I leads to recovery from type 1 diabetes. J Clin Invest. 2002; 109: 1153-63.

34. Kim JY, van de Wall E, Laplante M, Azzara A, Trujillo ME, Hofmann SM, et al. Obesity-associated improvements in metabolic profile through expansion of adipose tissue. J Clin Invest. 2007; 117: 2621-37.

35. Grundy SM, Mok HY, Zech L, Steinberg D, Berman M. Transport of very low density lipoprotein triglycerides in varying degrees of obesity and hypertriglyceridemia. J Clin Invest. 1979; 63: 1274-83.

36. Howard BV. Insulin resistance and lipid metabolism. Am J Cardiol. 1999; 84: 28J-32J.

37. Ruotolo G, Howard BV. Dyslipidemia of the metabolic syndrome. Curr Cardiol Rep. 2002; 4: 494-500.

38. Camps L, Reina M, Llobera M, Bengtsson-Olivecrona G, Olivecrona T, Vilaro S. Lipoprotein lipase in lungs, spleen, and liver: synthesis and distribution. J Lipid Res. 1991; 32: 1877-88.

39. Park SY, Kim HJ, Wang S, Higashimori T, Dong J, Kim YJ, et al. Hormone-sensitive lipase knockout mice have increased hepatic insulin sensitivity and are protected from short-term diet-induced insulin resistance in skeletal muscle and heart. Am J Physiol Endocrinol Metab. 2005; 289: E30-9. 